\title{
The Potential Influence of Youtube as a Means of Disseminating the Findings of Research to Millennial-Aged Teachers
}

\author{
Michael BondClegg and Nancy Maynes (corresponding author) \\ Nipissing University, Schulich School of Education \\ 100 College Dr. \\ North Bay, Ontario, CANADA \\ P1B 8L7
}

Received: March 27, 2018 Accepted: April 23, 2018 Published: May 1, 2018

doi:10.5296/jse.v8i2.12898 URL: https://doi.org/10.5296/jse.v8i2.12898

\begin{abstract}
This study sought to discover if the means by which research was presented could influence teachers' attitudes towards research. Survey and interview methodologies were used in the study. Findings included participants' feeling that video may not provide the details that teachers would need to put the findings of the study into practice. They also indicated that follow-up professional learning would be required after video viewing. Participants' level of accuracy regarding the findings of written or video research reports was low, at about $50 \%$ accuracy. While the group receiving the YouTube version of the study almost exclusively stated a high likelihood to access research presented in this format again, the group who received the written version of the study was not enthusiastic towards accessing written research in the future. It was not clear whether format has a notable influence on tendencies to use research to support professional learning and practice. As our information consumption tendencies trend towards mediums that promote rapid consumption, researchers should be aware that their work might be made more effectively available to young teachers by being presented in the format of a video, such as those hosted on YouTube.
\end{abstract}

Keywords: Millenial teachers, research access practices of teachers, YouTube 


\section{Introduction}

Teaching has been acknowledged as an art form that is balanced with science. Marzano (2007), for example, titled one of his most widely known works The Art and Science of Teaching to illustrate this balance. While anyone involved in the profession can acknowledge that there is a certain nuanced artistry to effective teaching, it has also been acknowledged that this artistry must be rooted in scientific approaches (Berliner, 1987):

No one I know denies the artistic component to teaching. I now think, however, that such artistry should be research-based. I view medicine as an art, but I recognize that without its close ties to science it would be without success, status, or power in our society. Teaching, like medicine, is an art that also can be greatly enhanced by developing a close relationship to science. (p. 4)

With regards to novice teachers, Stanovich and Stanovich (2003), in their comprehensive work, Using Research and Reason in Education: How Teachers Can Use Scientifically Based Research to Make Curricular and Instructional Decisions (2003), observe:

Education is informed by formal scientific research through the use of archival research-based knowledge such as that found in peer-reviewed educational journals. Preservice teachers are first exposed to the formal scientific research in their university teacher preparation courses (it is hoped), through the instruction received from their professors, and in their course readings (e.g., textbooks, journal articles). (p. 4)

The question is, where do novice teachers go from here? We acknowledge that, hopefully, pre-service education provides teachers with the opportunity to get to know research as a means to form the basis of their practice. However, this basis of practice may be underdeveloped and may not impact student learning as much as it possibly could if it was consistently informed by research-based findings.

Stanovich and Stanovich (2003) argue that "as professionals, teachers can become more effective and powerful by developing the skills to recognize scientifically based practice" ( $p$. 2). The use of research, therefore, takes some of the guesswork out of effectively facilitating student learning. Research provides the justification for engaging in a particular teaching strategy, beyond just intuition, recommendation, or familiarity. This is important, argue Stanovich and Stanovich (2003), as "Teaching methods should lead to students learning the outcomes that are the focus of the assessment standards" and that in order to reach students more effectively, teachers need to be accessing "Published findings of research-based evidence that the instructional methods being used...lead to student achievement" (p. 2).

Malouf and Schiller (1995) argued for the "potential of research as a source of new educational approaches and understandings - a 'wellspring' for educational innovations" ( $p$. 422). In this estimation, research allows teachers to develop their practice with the confidence of knowing that a strategy that they are going to employ has had some demonstrated effectiveness in previous situations, even if that approach is novel.

What research does offer, with regards to improving student learning, is value in taking the 
guesswork out of instructional decisions. Through the use of research, teachers can draw on the experience of experts in their field who have worked to shed light on how educators can have the greatest impact on their students. By utilizing research to develop their practice, teachers can feel comfortable in the idea that they are not expected to devise methods independently that they suspect will have an impact, but rather that the research can be an ally in the pursuit to maximize positive effects on student learning and achievement.

\section{The Purpose of this Study}

Previous researchers have shown that research informed practice may result in improvements in learning. However, we appear to know little about how early career teachers can acquire this facility to use research effectively to inform their practice. Therefore, the question to be examined in this study is: Can the means by which research is presented influence teachers' attitudes towards, and likelihood to use, research in order to support their professional learning and practice?

\section{Literature Review}

Via his work examining teachers' use of research, Rickinson (2005) suggests that there is a range of factors that can facilitate or hinder access to and engagement with research, including: focus and form of the research, the interests and background of the practitioners, the professional context in which the research is utilized, and the wider context of support for the communication of knowledge (p. 4). Due to its familiarity to millennial teachers, YouTube becomes a logical place where we might take research and present it in a form and format that is engaging and provides ongoing support (in the form of comment forums) in order to appeal to this demographic. Based on their work surveying pre-service teachers' attitudes towards research, Gitlin, Barlow, Burbank, Kauchak, and Stevens (1999) suggest that, "If future teachers are to engage in research, they need to find diverse ways to find out about research" (p. 761). They recommend that research be presented in a more easily accessible format, one that does not make overuse of "academic codes" (p. 767), makes valuable use of teachers' time, and is easily assessable in terms of physically obtaining the research. A YouTube channel, housing videos based on the findings of research, would seem to satisfy these criteria and potentially make the research more appealing to millennial consumers.

Format of research is only one piece of the equation when it comes to teacher utilization. Cochran-Smith and Lytle (1993), argue that the problem with research utilization is not in simply getting research to practitioners, but rather in ensuring that the research is practically relevant (p. 41). Lysenko, Bernard, Dagenais, Abrami, Ramde, and Jonosz (2012) noted similar trends in the literature, pointing out that teachers' attitudes towards research tend to be influenced by relevancy (p. 301).

While there is considerable literature documenting teachers' use of, and attitudes towards, published research, we need to evaluate how teachers' attitudes may differ when research is presented in contemporary formats. The focus of literature concerning teachers' attitudes towards research is currently concerned with only one format of research - published written 
work - and does not consider teachers' attitudes when research is offered in more contemporary formats, such as online video.

\subsection{The safeguarding provided by peer-reviewed research}

Teachers are bombarded with information on a daily basis: information about the activities of the school community, communication with parents and students, and information about board and district policies, among others. One of the types of information teachers encounter on a regular basis is information regarding various instructional strategies that they can employ in a given situation. This information comes in many forms such as blogs, Twitter feeds, and advice from administrators and colleagues. While these can all be worthwhile sources of information, the information itself is made stronger if it has passed through the safeguarding stage of peer review. When discussing the deluge of information encountered by teachers, Stanovich and Stanovich (2003) argue that, "The public criteria of peer review... [exists] in part to keep checks on the objectivity of individual scientists" (p. 19). This criterion makes it more difficult for a researcher to hide his or her bias and attempt to disseminate information that may be rooted in anecdotal evidence or pseudoscience rather than actual, repeatable results. Despite this fact, "Not all information in peer-reviewed scientific journals is necessarily correct, but it has at the very least undergone a cycle of peer criticism and scrutiny" (p. 9). This scrutiny in peer-reviewed literature can act as a "diagnostic tool" (Stanovich \& Stanovich, 2003, p. 9). If a particular teaching strategy being explored by a teacher fails to appear, or appears sparsely, in peer-reviewed literature, the teacher can take this as a sign that this particular practice may not necessarily be of maximum benefit to his/her students. Indeed, in an era and profession where people are bombarded with information at all turns, the peer-review process, though not perfect, "really is the only external consumer protection that teachers have" (Stanovich \& Stanovich, 2003, p.10).

\subsection{Teachers' attitudes towards published research - What does the literature say?}

Despite the extensive time and effort that goes into developing and publishing peer-reviewed educational research, teachers do not often use published research as a "go-to" source for developing their practice. Lysenko et al. (2012) conducted a review of the empirical research on practitioners' use of research to influence their teaching practice, noting that:

Commentators have claimed that school practitioners continue to make little use of educational research in their classroom practice (e.g., Dagenais et al., 2008; Hannan et al., 1998; Nutley et al., 2003; Rohrbach et al., 2005). Numerous authors emphasize the fact that, despite an increasing mobilization of researchers and research-funding agencies, the literature on research use continues to yield little evidence on the processes involved, and even less on the effects of efforts to promote their use (Davies et al., 2005; Estabrooks, 2007; Mitton et al., 2007; Nutley et al., 2007). (p. 286)

Lysenko et al., (2012) concluded that, "not much is known about the ends to which practitioners apply research in their teaching practice" (p. 295). They did notice, however, that the literature suggests a relationship between teachers' attitudes towards research and their likelihood to use that research in order to influence their practice (p. 296) and outlined 
several factors influencing practitioners' attitudes towards research. Interestingly, many of the conclusions from this review point to factors of communication as key determinants of teachers' use of research. A lack of "sustained interactivity between researchers and practitioners" (p. 300), the method used to communicate the research, a preference for internet-based communication methods, and the ability of teachers to find research that fits their specific needs (p. 301), were all explicitly referenced as reoccurring determinants in the studies that were reviewed.

The findings of Lysenko et al. (2012) are important, as they suggest a lack of use of research by teachers for a variety of reasons, many of which stem from the method by which the research is communicated. This suggests that, under the right circumstances, practitioners may be more likely to utilize research to inform their practice, as long as it is communicated in a way suitable to the target audience. This may prove to be an encouraging finding for researchers, as it points to a possible method by which researchers can make their work more accessible, and potentially more frequently utilized, to benefit student learning.

Gitlin, Barlow, Burbank, Kauchak, and Stevens (1999) suggest that research might be more frequently utilized by teachers if it was more physically and linguistically accessible (p. 767). In contrast to this, Cochran-Smith and Lytle (1993), suggest that a lack of research utilization might not stem only from the physical availability of research, but also from researchers' inability to meet the timely needs of teachers (p. 41).

This theme of a divide between researcher and teacher is echoed in the surveys conducted by Gitlin et al., (1999), who noted that teachers who were surveyed said they were not inclined to utilize research in their professional learning because they felt no personal connection to the researchers themselves (p. 764). This lack of relationship between researchers and practitioners is expanded upon by Landrum, Cook, Tankersley and Fitzgerald (2002), who point out that, "teachers rated professional journals and college coursework as generally less trustworthy than their own colleagues" (p. 46).

This tendency to consult colleagues is certainly noted in the literature surrounding research utilization. In a survey of 390 British teachers, William and Coles (2003) found that one of "the most frequently used sources [of research] are colleagues" (p. 13). The surveys conducted by Gitlin et al., (1999) also suggested that teachers are significantly more likely to consult like-minded, experienced colleagues rather than the relevant educational research (pp. 757, 760-764).

\subsection{The potential harm of collegial input over research-based professional learning}

Seeking professional advice from colleagues, while perhaps comfortable and convenient, might not always lead to learning that most effectively impacts students, especially in the context where many Millennial practitioners could be considered novice teachers.

If the literature suggests that teachers, especially novice teachers, are more likely to consult colleagues as a source of professional learning, rather than published research, it is important to delve into the possible dangers of this practice. In their work with novice teachers participating in an induction program, Chubbuck, Clift, Allard and Quinlan (2003) found 
interesting observations when it came to the relationships novice teachers formed with their colleagues. They found that some of these relationships might be dangerous when novice teachers seek to further their theoretical knowledge of teaching:

When novice teachers discuss innovative theories acquired in pre-service training with veteran teachers who hold those pre-service institutions in a certain amount of disdain for being out of touch with the "real world" of the field, novices are even less safe in pursuing the critical examination of practice that is so crucial to their growth and participation in educational improvement... This could potentially lead to a teacher abandoning solid practices learned in teacher education programs, in favour of practices recommended by their colleagues. (pp. 372-373)

A second possible danger noted by Chubbuck et al., (2003) is the notion that "supportive sharing of stories without the challenge to explore alternative methods and solutions can cripple a beginning teacher's growth as novices play it safe inside collaborative commiseration" (p. 374).

This speaks to a need for novice teachers to consult outside resources such as peer-reviewed research, to further their professional development. These researchers also acknowledge that, "Outside sources...help new teachers explore alternative methods of creating educational improvement" (p. 375), without the pressure of feeling beholden to the practices of their colleagues. The teachers involved in the study by Chubbuck and colleagues found that a "research-based support group" was beneficial to the extension of teachers' practices (p. 373). This feeling is supported by the work of Winkler (2001) who noted that an "active engagement with theoretical thought can provide teachers with a different mental 'space' within which they can reflect on their experience in qualitatively new ways" (p. 446) and by, Hogan, Rabinowitz and Craven (2003), who recommended professional development programs rooted in research to help teachers move from novice to expert teaching domains.

All of these observations should not be misconstrued as being in opposition to collegiality. Collegiality, characterized by "purposeful adult interactions about improving school-wide teaching and learning" (Glickman, Gordon,\& Ross-Gordon, 2014, p. 10) is a necessary part of an effective school. Multifaceted in its impact, Jarzabkowski (2002) notes that collegiality is an important part of the working environment, supporting both the emotional well-being of teachers, and the development of a strengthened workplace, which may benefit students.

In relation to novice teachers, collegiality is especially valuable insofar as self-efficacy is concerned. In a study of 225 teachers, Tschannen-Moran and Hoy (2007) observed that support of colleagues was a contributing factor in the increase of novice teachers' self-efficacy (p. 22). However, the same study found that "mastery experiences" of effective teaching practice accounted for the greatest contribution to a novice teacher's sense of efficacy (p. 23). This seems to suggest a need for balance in teachers' seeking of information from outside research, alongside their colleagues. 


\subsection{Effective versus ineffective teaching}

While there is considerable literature regarding teaching strategies that can be considered effective, not much information is available on ineffective teaching strategies. Rather, ineffective teaching seems to be a by-product of a lack of effective teaching strategies. Hattie (2004) states that, "few [teachers] do damage, some maintain a status quo in growth of student achievement and many [teachers] are excellent" (p. 4) and suggests that teachers who would be considered excellent achieve their excellence because they are utilizing and actively aware of their utilization of, research-based teaching strategies. Marzano (2007) further argues that research can lead teachers to effective teaching strategies, noting that, "the science part of effective teaching is founded on decades of research that has provided guidance for the general categories of behaviors that constitute effective teaching and for the specific techniques that can be employed within those general categories" (p. 191). In light of these observations, it is imperative that teachers access these research-based practices in order to enhance student learning most effectively.

3.5 Millennial teachers: Digital preferences and the need for research to support their practice

The lack of enthusiasm towards published research speaks, perhaps, to a broader cultural shift in terms of how information is consumed in the 21 st century and raises the question of how researchers and administrators can more effectively share the findings of research in a way that is more indicative of contemporary media. This study concerns itself with those born into what is called the "Millennial" generation (Howe, Strauss\& Matson, 2000). It has been noted in literature profiling this generation that Millennials have a distinct preference for digital media (Prensky, 2004; Donnison, 2007), with Green (2000) and Pekala (2001) noting that professional environments should amend their practices in order to appeal to the digital expectations of Millennials. Donnison argues that these shifts in practice should be adjusted to align to Millennials' desire for immediacy, as well as to account for their "short attention span and a propensity to boredom" (p. 6). Donnison further points out consistencies in the literature that emphasize Millennials' "over-confidence in their own abilities" (p. 6). In an educational setting, this over-confidence could lead to novice teachers assuming that their practice is more indicative of an expert than it actually is. This speaks to the need for external support for novice teachers - support that is based on peer-reviewed research. Donnison echoes this suggestion by calling for teacher education programs to offer, "pedagogically appropriate teaching and learning strategies for... Millennial students...[which] must be informed by educational research..." (p. 9).

\subsection{YouTube as a possible outlet to distribute research-based content to Millennial teachers}

As much of the literature suggests that Millennials have a tendency to gravitate towards digital media, an obvious choice for how researchers can effectively target this audience might in the form of digital media. While there are seemingly endless platforms via which the findings of research could be shared, a popular modality would be the video sharing website YouTube. YouTube is an online video sharing website that allows users to view, as well as upload, content directly to "channels" which they manage as both consumers and producers. 


\section{$\triangle$ Macrothink}

The content on YouTube is easily searchable (powered by Google's search platform) and allows open communication via forums for comments and discussion for both content creators and consumers.

Currently, the use of YouTube could be considered ubiquitous:

- YouTube has over a billion users - almost one-third of all people on the Internet — and every day people watch hundreds of millions of hours on YouTube and generate billions of views.

- YouTube overall, and even YouTube on mobile alone, reaches more 18 - 34 and 18 - 49 year-olds than any cable network in the U.S.

- Growth in watch time on YouTube has accelerated and is up at least 50\% year over year for three straight years.

- The number of people watching YouTube per day is up $40 \%$ year to year since March 2014. (YouTube, 2016)

It can be reasonably argued that YouTube is the most logical platform via which research can be disseminated to the teachers at a school. YouTube seemingly satisfies several criteria noted in the literature by Lysenko et al., (2012). Teachers want "sustained interactivity between researchers and practitioners" (p. 300); YouTube satisfies this criterion by allowing researchers posting material (or those posting on their behalf) to be able to interact with teachers via the discussion forums. YouTube further satisfies the criterion for the preference of Internet-based communication methods to disseminate research (p. 301). Finally, the search functionality of YouTube satisfies the criterion of practitioners being able to find research easily to fulfill their needs (p. 301).

As this platform will be familiar to the participants of this study and satisfies the above criteria, it may prove to be a useful way to generate enthusiasm towards, and use of, research-based teaching practices.

\section{Methodology}

Teachers who participated in this study were all employees of the American International School Kuwait. They were all currently teaching within one of three International Baccalaureate programmes - the Primary Years Programme, Middle Years Programme and/or Diploma Programme. In total, 23 teachers participated in the study $(n=23)$ and each participant was part of the Millennial generation. All participating teachers were within their first five years of experience as educators.

The study commenced at the beginning of the 2016/2017 school year, with participants taking an initial survey and participating in a preliminary round of interviews. Print and video research were distributed to participants within four weeks of the initial survey and interview. Two weeks following the distribution of the research to participants, a second round of interviews was conducted and the post-study survey was administered.

As noYouTube options currently existed that encapsulated the essence of this study 
(peer-reviewed research presented in the form of a YouTube video), the creation of a video option was needed. This is not to say that there are no videos for the purposes of professional learning published online. To the contrary, YouTube is full of videos for teachers to use as learning materials, but they are primarily presented as filmed PowerPoint presentations, or as case study profiles of particular classrooms or schools. These types of case study profiles were criticized by participants in a study by Zhang, Koehler, Lundeberg, and Eberhardt (2011) because these type of videos were often felt to be "out of context" for the learning of the teachers (p. 457). To avoid this feeling of being out of context, the video created for this study was simply a presentation of the research, not an example of one specific classroom using the research in action.

There are further suggestions provided in the literature for creating videos for professional learning. Jacobs, Hollingsworth, and Givvin (2007) highlight the advantages of working with digital video, especially in online environments both for the ease and convenience of the creator and consumer (p. 292). These are criteria which filming, by using a digital device and uploading to YouTube, were able to satisfy. When discussing the production of instructional video, though not video for teachers specifically, Moreno (2007) suggests that breaking the video into small manageable parts may increase its effectiveness. These techniques were taken into consideration during the creation of the video.

Further to these filmmaking techniques, the suggestions of participants in the Gitlin et al.,(1999) survey were used to inform the methodology behind the creation of this video, mainly related to the use of non-academic language and the relevance of the subject matter chosen for the video that was used in this study.

The published piece which was chosen for presentation to the study participants, in both written and video format, was Problem-Based Learning in K-12 Education: Is it Effective and How Does it Achieve its Effects? by Deanna Kuhn and Clarice Wirkala (2011). This particular study was chosen for three reasons. Firstly, this work is concerned with a methodology that is central to many of the teaching practices recommended within the IB program. Secondly, this work is sourced from the American Educational Research Journal, a source recommended to teachers by Stanovich and Stanovich $(2003$, p. 8) as being both peer-reviewed and of high repute. Thirdly, this work is concerned with $\mathrm{K}-12$ educators, which allowed for the broadening of the pool of possible participants to be sourced.

In order to get a clear picture of the effectiveness, or ineffectiveness, of each type of research distribution and in order to avoid the possible recency effect of participants receiving both the written and YouTube versions of the study, participants were randomly provided the aforementioned study either in its original written format, or in the format of a YouTube video. In order to determine which participants would receive each format of the study, simple random sampling in the form of a random numbers table was utilized, whereby half of the participants were chosen to receive the study in its original written form, while the other half was chosen to receive the study in YouTube format. Participants were given a period of two weeks within which to engage with the study, in whichever format they received it. Participants were under no obligation to engage with the study in either format, as their 
choice to $\mathrm{read} / \mathrm{view}$ the study would provide insight into the engagement level of each format and their attitudes towards taking the time to seek published research during the busy school year. If participants chose not to engage with the study provided, they were still invited to participate in both the follow-up interview and survey as, once again, their choice not to engage with the research could provide insight into both its ability to engage teachers, as well as teachers' attitudes towards research as a source of professional learning.

In total, the entire study encompassed a time period of approximately eight weeks. This time period hopefully provided enough time for participants to engage with material without overwhelming their schedule. The time frame may also have avoided allowing too much time to pass between when the participants received the research and the follow-up interviews regarding these sources of information. This timing was based on the assumption that the longer time passes between the distribution of the research and the follow-up interviews, the more of a factor time will be in teachers' decision to access these resources, rather than format - if the format is engaging, teachers will presumably give it their time.

Both surveys were based on a six-point scale of strongly disagree, disagree, somewhat disagree, somewhat agree, agree, and strongly agree. This scale was chosen to allow participants a wide degree of choice in their responses, with the hopes of providing more insightful data. Both the pre and post study interviews were comprised mainly of open-ended questions that allowed participants to explore their feelings regarding both formats of research and the effect these formats may have had on their practice; however some questions were of a yes/no or scale-based nature in order to collect additional quantitative data.

\section{Results}

As the main question being investigated via this study was regarding how format of research may or may not affect teachers' likelihood to utilize it within their practice, it is important to analyze the data of the survey results by comparing the results from participants who received the research study in its original, written form and those who received the research study in video form. Here, each statement was analyzed by comparing the preliminary survey results with the follow-up results, based on each group of participants.

\subsection{Comparison between the preliminary and follow-up survey data}

Statement 1 - Comparison by group. Overall, opinions regarding the value of published research as a source of professional learning remained largely the same throughout the course of the study. There were slight variances within each qualifier from preliminary survey to follow-up survey, however the amount of responses in both agree and disagree spectrums remained largely the same (see Table 1). Only the group receiving the written research study showed a shift of opinions from the agree spectrum to the disagree spectrum, with $10 \%$ of the participants shifting their response from one of agreement to one of disagreement. Across groups, the results are almost identical, with around $90 \%$ of participants selecting responses in the agree spectrum. 


\section{Macrothink}

Table 1. Comparison by group of participants' responses to the statement: Published research is a valuable source of professional learning for teachers.

\begin{tabular}{|l|l|l|l|l|}
\hline \multirow{2}{*}{ Qualifier } & \multicolumn{2}{|l|}{ Written format group } & \multicolumn{2}{l|}{ YouTube format group } \\
\cline { 2 - 5 } & $\begin{array}{l}\text { Preliminary } \\
\text { Survey }\end{array}$ & $\begin{array}{l}\text { Follow-up } \\
\text { Survey }\end{array}$ & $\begin{array}{l}\text { Preliminary } \\
\text { Survey }\end{array}$ & $\begin{array}{l}\text { Follow-up } \\
\text { Survey }\end{array}$ \\
\hline Strongly agree & $33.3 \%$ & $30 \%$ & $27.3 \%$ & $9.1 \%$ \\
\hline Agree & $66.7 \%$ & $30 \%$ & $63.6 \%$ & $54.5 \%$ \\
\hline Somewhat agree & $0 \%$ & $30 \%$ & $0 \%$ & $27.3 \%$ \\
\hline $\begin{array}{l}\text { Somewhat } \\
\text { disagree }\end{array}$ & $0 \%$ & $10 \%$ & $9.1 \%$ & $0 \%$ \\
\hline Disagree & $0 \%$ & $0 \%$ & $0 \%$ & $9.1 \%$ \\
\hline Strongly disagree & $0 \%$ & $0 \%$ & $0 \%$ & $0 \%$ \\
\hline
\end{tabular}

The lack of variance in this data, both within groups and across groups, suggests that participants continue to believe in the value that published research may hold for teachers' professional learning, which is consistent with the research of Gitlin et al., (1999).

Statement 2 - Comparison by group. Within both groups there was a shift in opinion from the agree spectrum to the disagree spectrum. The written format group showed a shift from $50 \%$ of participants agreeing that they prefer published research as a main source of their professional learning to $40 \%$. Likewise, the YouTube format group showed a shift from approximately $55 \%$ of the participants agreeing that they prefer published research as a main source of their professional learning to just over $45 \%$ agreement (see Table 2). When looking across groups, a slight difference can be noticed with $40 \%$ of the written format group in agreement with the statement compared to $45 \%$ of the YouTube format group in agreement with the statement. 


\section{Macrothink}

Journal of Studies in Education

ISSN 2162-6952

2018, Vol. 8, No. 2

Table 2. Comparison by group of participants' responses to the statement: I prefer published research as my main source of professional learning.

\begin{tabular}{|l|l|l|l|l|}
\hline \multirow{2}{*}{ Qualifier } & \multicolumn{2}{|l|}{ Written format group } & \multicolumn{2}{l|}{ YouTube format group } \\
\cline { 2 - 5 } & $\begin{array}{l}\text { Preliminary } \\
\text { Survey }\end{array}$ & $\begin{array}{l}\text { Follow-up } \\
\text { Survey }\end{array}$ & $\begin{array}{l}\text { Preliminary } \\
\text { Survey }\end{array}$ & $\begin{array}{l}\text { Follow-up } \\
\text { Survey }\end{array}$ \\
\hline Strongly agree & $0 \%$ & $10 \%$ & $0 \%$ & $0 \%$ \\
\hline Agree & $41.7 \%$ & $10 \%$ & $18.2 \%$ & $18.2 \%$ \\
\hline Somewhat agree & $8.3 \%$ & $20 \%$ & $36.4 \%$ & $27.3 \%$ \\
\hline $\begin{array}{l}\text { Somewhat } \\
\text { disagree }\end{array}$ & $16.7 \%$ & $40 \%$ & $27.3 \%$ & $18.2 \%$ \\
\hline Disagree & $33.3 \%$ & $10 \%$ & $18.2 \%$ & $27.3 \%$ \\
\hline Strongly disagree & $0 \%$ & $10 \%$ & $0 \%$ & $9.1 \%$ \\
\hline
\end{tabular}

Several researchers (Gitlin et al., 1999; Joram, 2007; Lysenko et al., 2012; Rickinson, 2005) have noted that, typically, teachers do not seek research to inform their practice, especially teachers (like those participating in this study) who are in the beginning stages of their careers.

Statement 3 - Comparison by group. When examining the likeliness to access research in written form, there was a significant change in both groups' responses. While just over $40 \%$ of the written format group indicated a preference for written research prior to the study, only $20 \%$ still felt this way following the study (see Table 3 ). 


\section{Macrothink}

Table 3. Comparison by group of participants' responses to the statement: I am more likely to access published research when it is in written form.

\begin{tabular}{|l|l|l|l|l|}
\hline \multirow{2}{*}{ Qualifier } & \multicolumn{2}{|l|}{ Written format group } & \multicolumn{2}{l|}{ YouTube format group } \\
\cline { 2 - 5 } & $\begin{array}{l}\text { Preliminary } \\
\text { Survey }\end{array}$ & $\begin{array}{l}\text { Follow-up } \\
\text { Survey }\end{array}$ & $\begin{array}{l}\text { Preliminary } \\
\text { Survey }\end{array}$ & $\begin{array}{l}\text { Follow-up } \\
\text { Survey }\end{array}$ \\
\hline Strongly agree & $0 \%$ & $0 \%$ & $0 \%$ & $0 \%$ \\
\hline Agree & $16.7 \%$ & $10 \%$ & $0 \%$ & $0 \%$ \\
\hline Somewhat agree & $25 \%$ & $10 \%$ & $63.6 \%$ & $36.4 \%$ \\
\hline $\begin{array}{l}\text { Somewhat } \\
\text { disagree }\end{array}$ & $25 \%$ & $20 \%$ & $18.2 \%$ & $27.3 \%$ \\
\hline Disagree & $33.3 \%$ & $30 \%$ & $18.2 \%$ & $36.4 \%$ \\
\hline Strongly disagree & $0 \%$ & $30 \%$ & $0 \%$ & $0 \%$ \\
\hline
\end{tabular}

When looking at the YouTube format group, there is an even more drastic change in opinion, with $63.6 \%$ of participants indicating a preference for research in written form prior to the study, and only $36.4 \%$ indicating a similar preference at the conclusion of the study.

Statement 4 - Comparison by group. Both groups were in agreement with the statement "I am more likely to access published research when it is in video form." prior to and following the study, with $100 \%$ of participants selecting responses in the agree spectrum at the conclusion of the study (see Table 4). 


\section{Ml Macrothink}

Table 4. Comparison by group of participants' responses to the statement: I am more likely to access published research when it is in video form.

\begin{tabular}{|l|l|l|l|l|}
\hline \multirow{2}{*}{ Qualifier } & \multicolumn{2}{|l|}{ Written format group } & \multicolumn{2}{l|}{ YouTube format group } \\
\cline { 2 - 5 } & $\begin{array}{l}\text { Preliminary } \\
\text { Survey }\end{array}$ & $\begin{array}{l}\text { Follow-up } \\
\text { Survey }\end{array}$ & $\begin{array}{l}\text { Preliminary } \\
\text { Survey }\end{array}$ & $\begin{array}{l}\text { Follow-up } \\
\text { Survey }\end{array}$ \\
\hline Strongly agree & $16.7 \%$ & $30 \%$ & $36.4 \%$ & $27.3 \%$ \\
\hline Agree & $41.7 \%$ & $50 \%$ & $36.4 \%$ & $45.5 \%$ \\
\hline Somewhat agree & $33.3 \%$ & $20 \%$ & $27.3 \%$ & $27.3 \%$ \\
\hline $\begin{array}{l}\text { Somewhat } \\
\text { disagree }\end{array}$ & $0 \%$ & $0 \%$ & $0 \%$ & $0 \%$ \\
\hline Disagree & $8.3 \%$ & $0 \%$ & $0 \%$ & $0 \%$ \\
\hline Strongly disagree & $0 \%$ & $0 \%$ & $0 \%$ & $0 \%$ \\
\hline
\end{tabular}

Interestingly, when looking at the results from the YouTube format group, a reduction was seen in the amount of participants who "strongly agreed" that they would be more likely to access research in video form. This may indicate that these participants did not enjoy the format of the video as much as they thought they might prior to the study. It also may indicate participants' expectations not being fulfilled by the video in terms of its production (length, clarity of ideas, trustworthiness of presenter, camera angles, shot selection, music, etc.).

\subsection{Comparison between the preliminary and follow-up interview data}

In comparing the data it was important to note that there were several $(n=5)$ participants who did not engage with either the video or written version for the research study provided. In total, one participant in the YouTube format group did not watch the video, while four participants in the written format group did not read the study.

Of the twelve participants receiving the written research study, one person stated that he read the entire study; seven people stated that they read certain parts of the study (typically the introduction, conclusion and implications), while four participants did not read the study at all. The stated reasons for either not reading the entire article, or not reading the article at all were similar, with the majority of participants expressing that they did not have time to read the study, or that the study was too long and the language within the study was alienating. The one person who did read the entire study stated, "I liked the title "problem-based learning' and I felt that it would be useful possibly in my teaching". 
Of the eleven participants receiving the video, nine stated that they watched the entire video, one person watched part of the video, while one person did not watch the video at all. The majority of participants who watched the entire video said they did so in order to fulfil their obligations for participation in this study. Two participants stated they watched the video because the content piqued their interest, while the participant who did not watch the video and the participant who only watched part of the video said they did not watch due to a lack of time.

Based on the difference between numbers of participants who engaged with the video versus those who engaged with the written study, it could be concluded that length of time needed for consumption is a major factor in a teacher's likelihood to engage with research. This does not necessarily indicate that video is a superior medium of communicating peer-reviewed research, only that (in this case) the amount of time needed to consume the video was significantly less than the amount of time needed to consume the written article and therefore was more appealing to teachers with busy schedules.

Of the six people who engaged with the written study, two said they enjoyed the format, while four said they did not. Reasons for enjoying the written study centered on the familiarity and consistency one can expect when reading a research study. Of the four who said they did not enjoy the format of the written study, responses were similar to those who did not read the study at all, with length of paper and academic language being common themes mentioned during the interview as reasons for their lack of enjoyment.

Of the nine people who engaged with the video, eight said they enjoyed the format, while one said she did not. Reasons for enjoying the video format centered on its shorter length, the fact that it could be consumed while one was at the gym and the conversational nature of the video. Several participants noted that it was nice to hear someone's voice explaining something over top of visuals and text, noting that it felt more like attending a seminar or learning in a classroom-like setting. Another interesting note regarding the video was one participant's observation that when you choose to read an article, you can never be one hundred per cent sure of how long it will take you to read it, while with a video you can be sure as to how long the video is going to take to watch by looking at the timeline. The person who said she did not like the format of the video said that she felt it was "too long"and that she did not have time to watch such long videos (in this case, eight minutes and 46 seconds). This observation is consistent with the majority of the participants in this study who note that time is a key factor in how they choose to engage in professional learning. Several participants who engaged in the video did note that they missed the opportunities that written studies provide to highlight and take notes. Many of these participants commented that watching the video helped them develop awareness of their needs as learners and prompted them to re-watch the video while taking notes by hand.

Interestingly, when asked about implementation of problem-based learning, the group who read the written article showed a higher ratio of those who felt comfortable implementing the findings of the research in their practice when compared to the YouTube format group. Three out of eight participants with valid responses in the written format group said they felt 
comfortable implementing the findings of the study in their practice, while only one out of six from the YouTube format group felt this way.

Of those who watched the video study and indicated that they did not feel comfortable implementing the findings of the study, a common theme emerged that the video felt like an introduction to the topic of problem-based learning. Several participants stated that after watching the video, they felt they would still need to do some follow-up learning in order to feel fully comfortable using problem-based learning in their classrooms. This is in contrast to those in the written format group who stated they did not feel comfortable implementing problem-based learning, and were generally found to indicate that they did not read the entire study.

Of those who felt comfortable implementing problem-based learning, responses were similar for both groups, with participants indicating that they felt the source (written or video) gave them all the information they would need to implement the findings of the study.

Of particular interest for this study was the degree of accuracy with which participants responded to the prompt, "Explain what you feel you can now apply to your practice, having acquired information through this format". Whether written format, or YouTube format group, the degree of accuracy with which participants spoke about the problem-based learning study was about 50\%.

While not the topic of this study, it is interesting to note that, in either format, participants' assimilation of the information was only accurate about half the time. This could possibly be due to the fact that participants only had one source of information on which to base their learning. It could also be due to the amount of time between engaging in the study and participating in the interview. This may also indicate some relationship between teachers' motivation to seek research and their corresponding attention to what they find.

Of the ten participants who watched some or all of the video, three indicated they would need to read the study that the video was based on in order to understand and apply its findings. Two participants qualified their response by saying that if they trusted the source of the video, or if it had been recommended by a person they trusted, or an administrator, then they did not feel they would need to follow-up and read the study. One participant again commented on the desire to highlight text and that following-up to read the study would fulfil that need. It is interesting to note that in responses to question four, the majority of the video format group indicated that they felt the video was a "good start" to their understanding of problem-based learning and that they would need to conduct more learning in order to understand it. However, here the majority of participants indicated they would not want to follow-up to read the research study that informed the creation of the video. This is possibly due less to a lack of desire to learn and more to a lack of desire to interact with research articles, as both surveys would suggest.

\section{Conclusions}

There were several key findings of this study. First, it was evident from both the surveys and interviews conducted, that teachers understand the value of peer-reviewed research for its 
ability to support professional practice effectively. Despite this understanding, however, participants focused heavily on the notion that they do not often have the time required to engage with this type of research. To this end, participants were enthused by the idea of peer-reviewed research being presented in the form of a YouTube video. The pervasive feeling was that since YouTube video is more convenient to watch (participants cited watching the video provided in this study on their phones and at the gym) and generally takes less time to consume, it would be a more desirable medium by which peer-reviewed research could be presented. This feeling was confirmed through action, as all but one participant engaging with the YouTube version of the study watched the video, while only one participant engaging with the written version of the study read the entire article.

Other notable findings included participants' feeling that while video was a more convenient way by which to consume peer-reviewed research, the video provided in this study did not include all of the information needed to put the findings of the study into practice and that follow-up professional learning would be required. Of interest was the observation that when discussing the contents of both the written and YouTube versions of this study, participants' level of accuracy regarding the findings was low, at about 50\% accuracy. Finally, a significant finding was participants' perceived likelihood to access each format type in the future. While the group receiving the YouTube version of the study almost exclusively stated a high likelihood to access research presented in this format again (a mean indication of 4.1 on a 5-point scale of likelihood to access again), the group receiving the written version of the study was not as enthusiastic towards accessing written research in the future (a mean indication of 1.9 on a 5-point scale of likelihood to access again).

\subsection{Implications}

The first major implication of this study is the attitude of teachers towards peer-reviewed research. This has been noted in the literature up to this point (Gitlin et al., 1999; Lysenko et al., 2012), especially concerning teachers who are near the beginning of their teaching careers (Gitlin et al., 1999; Joram, 2007; Rickinson, 2005), as per the participants in this study. While it is clear, via this study, that Millennial-aged teachers see peer-reviewed research as a valuable source of professional learning, it is also clear that none of these teachers is interested in accessing this type of professional learning resource, when it is in written format. This finding is consistent with previous literature, with a major difference in this study being the option for teachers to seek peer-reviewed research in a potentially more engaging and convenient format to a traditional, written presentation. The potential of YouTube videos to intrigue Millennial-aged teachers could have implications for researchers and publishers, who may consider creating video versions of their findings in order to appeal to a wider and increasingly younger audience.

The appeal of professional learning that takes little time to consume is another consideration that researchers may want to be mindful of when publishing their findings. Time was cited by almost every participant in this study as a key factor for engaging with, or not engaging with, the distributed piece of research, either in written or video format.

It would seem that research studies delivered in the format of a YouTube video, may carry 
greater potential to engage younger teachers than research studies presented in written format. The typically compressed timeframe of video media may appeal to teachers with busy schedules and offer a more manageable entry-point for engaging with research. Several participants in this study cited not only the shorter time frame it takes to consume a video, but also the knowledge of exactly how long it would take them to consume the video, as attractive features of research presented in this format and one of the major reasons that video holds a greater appeal than written articles.

Secondly, video allowed participants to gain, at least, an equally solid foundational understanding of the findings of the research presented within, as did the written study. This finding may prove advantageous for administrators looking to provide their staffs with valuable foundational information, without burdening their staffs with time-consuming readings. By creating video versions of peer-reviewed studies, administrators can reduce the time and costs typically involved with providing a reading to their staffs. This might allow administrators to maximize time spent in professional learning and professional development sessions, while at the same time providing staffs with sound, research-based practices.

Finally, the majority of participants engaging with the YouTube version of the study indicated that they would like to continue their professional learning around the topic presented in the video. The ability of video to intrigue or "tune-in" teachers to new practices may potentially provide inroads for researchers to encourage teachers towards their work. Video, in this case then, becomes a means for researchers and publishers to attract a wider audience to their work and potentially to engage novice teachers with best practices on a more ongoing basis (i.e., outside of in-service professional development or graduate-level education). Furthermore, this finding might provide administrators with a means by which to catalyze staff professional learning towards a certain topic, strategy, or intervention.

\subsection{Recommendations for further study}

If researchers were interested in further pursuing the potential influence of YouTube as a means for professional learning, several avenues could be explored. As mentioned above, it would be interesting to reproduce a similar study with a video and article that took a similar length of time to consume. This might yield more accurate feedback with regards to research in written format.

A longer-term study would be interesting, in order to see teachers' tendencies to apply the findings of research to their practice and whether or not those tendencies were influenced by the format of research with which they were engaging. During such a study, it would also be interesting to compare the effectiveness with which teachers apply the findings of a variety of studies and whether or not format plays a role in the effectiveness of implementation. Further to this, an investigation could be conducted on teacher's tendencies to use different formats of professional learning, such as magazines, blogs and online sources of information such as ASCD and whether or not teachers find accessing these other web-based publications to be an effective use of their time.

Narrowing in specifically on research presented in video format, a further study could be 
conducted whereby teachers' tendencies to conduct additional professional learning following the viewing of a research video, is measured. This would potentially generate greater insight into the notion presented here that video might be an inroad for researchers looking to intrigue and engage a wider, younger audience. Finally, a comparative analysis could be conducted between teachers' confidence in the findings of research they read, versus their confidence in the findings of research that they view.

\section{Discussion}

This study sought to discover if the means by which research was presented could influence teachers' attitudes towards, and likelihood to use, research in order to support their professional learning and practice. While it was evident that teachers participating in this study clearly preferred information presented in video, rather than in written format, what is not clear is whether that format has a notable influence on tendencies to use this research to support professional learning and practice. It was also clear that the time needed to engage in professional learning was seen as a key factor in preferring video to written formats. As our information consumption tendencies continue to trend towards mediums that promote rapid consumption, researchers should be aware that their work might be made more effectively available to young teachers by being presented in the format of a video, such as those hosted on YouTube. However, it must be noted that further study is required to determine what effect, if any, the potential increase in consumption of video may provide to enrich classroom practice and student learning.

\section{References}

Berliner, D. C. (1987). Knowledge is power: A talk to teachers about a revolution in the teaching profession. In D. C. Berliner \& B. V. Rosenshine (Eds.), Talks to teachers (pp. 3-33). New York: Random House.

Chubbuck, S. M., Clift, R. T., Allard, J., \& Quinlan, J. (2003). Playing it safe as a novice teacher: Implications for programs for new teachers. Journal of Teacher Education, 52(5), 365-376. https://doi.org/10.1177/0022487101052005003

Cochran-Smith, M., \& Lytle, S. L. (1993). Inside outside: Teacher research and knowledge. New York: Teachers College Press.

Donnison, S. (2007). Unpacking the Millennials: A cautionary tale for teacher education. Australian Journal of Teacher Education, 32(3). https://doi.org/10.14221/ajte.2007v32n3.1

Gitlin, A., Barlow, L., Burbank, M. D., Kauchak, D., \& Stevens, T. (1999). Pre-service teachers' thinking on research: Implications for inquiry oriented teacher education. Teaching and Teacher Education, 15(7), 753-769. https://doi.org/10.1016/S0742-051X(99)00015-3

Glickman, C. D., Gordon, S. P., \& Ross-Gordon, J. M. (2014). SuperVision and instructional leadership: A developmental approach (9th ed.). United States: Pearson.

Green, M. (2000). Beware and prepare: The government workforce of the future. Public Personnel Management, 29(4), pp.435-444. https://doi.org/10.1177/009102600002900402 
Hattie, J. (2004). Teachers Make a Difference: What is the research evidence? Retrieved from http://www.educationalleaders.govt.nz/Pedagogy-and-assessment/Building-effective-learning -environments/Teachers-Make-a-Difference-What-is-the-Research-Evidence

Hogan, T.M., Rabinowitz, M., \& Craven, J. (2003), Problem representation in teaching: Inferences from research of expert and novice teachers. Educational Psychologist, 38, 235-247. https://doi.org/10.1207/S15326985EP3804_3

Howe, N., Strauss, W. A., \& Matson, R. J. (2000). Millennials rising: The next Great Generation. New York: Knopf Doubleday Publishing Group.

Jacobs, J. K., Hollingsworth, H., \& Givvin, K. B. (2007). Learned from the TIMSS video studies video-based research made "easy": Methodological lessons. Field Methods, 19(3), 284-299. https://doi.org/10.1177/1525822X07302106

Jarzabkowski, L. M. (2002). The social dimensions of teacher collegiality. Journal of Educational Enquiry, 3(2), 1-20.

Joram, E. (2007). Clashing epistemologies: Aspiring teachers', practicing teachers', and professors' beliefs about knowledge and research in education. Teaching and Teacher Education, 23(2), 123-135. https://doi.org/10.1016/j.tate.2006.04.032

Kuhn, D., \& Wirkala, C. (2011). Problem-based learning in K-12 education: Is it effective and how does it achieve its effects?. American Educational Research Journal, 48(5), 1157-1186. https://doi.org/10.3102/0002831211419491

Landrum, T. J., Cook, B. G., Tankersley, M., \& Fitzgerald, S. (2002). Teacher perceptions of the trustworthiness, usability, and accessibility of information from different sources. Remedial and Special Education, 23(1), 42-48. https://doi.org/10.1177/074193250202300106

Lysenko, L., Bernard, R., Dagenais, C., Abrami, P. C., Ramde, J., \& Janosz, M. (2012). Use of research-based information by school practitioners and determinants of use: A review of empirical research. Evidence \& Policy, 8(3), 285-309. https://doi.org/10.1332/174426412X654031

Malouf, D. B., \& Schiller, E. P. (1995). Practice and research in special education. Exceptional Children, 61(5), 414-424. https://doi.org/10.1177/001440299506100502

Marzano, R. J. (2007). The art and science of teaching: A comprehensive framework for effective instruction. Alexandria, VA: Association for Supervision and Curriculum Development.

Moreno, R. (2007). Optimising learning from animations by minimising cognitive load: Cognitive and affective consequences of signaling and segmentation methods. Applied Cognitive Psychology, 21(6), 765-781. https://doi.org/10.1002/acp.1348

Pekala, N. (2001). Conquering the generational divide. Journal of Property Management, $66(6), 30-37$. 


\section{Macrothink}

Prensky, M. (2004). The Emerging Online Life of the Digital Native: What they do differently because of technology, and how they do it. Retrieved from http://www.marcprensky.com/writing/Prensky-The_Emerging_Online_Life_of_the_Digital_ Native-03.pdf

Rickinson, M. (2005, October). Practitioners' use of research: A research review for the National Evidence for Education Portal (NEEP) Development Group. (Working Paper). London: National Educational Research Forum.

Stanovich, P. J., \& Stanovich, K. E. (2003). Using research and reason in education: How teachers can use scientifically based research to make curricular \& instructional decisions. Retrieved from https://www.nichd.nih.gov/publications/pubs/Pages/using_research_stanovich.aspx

Tschannen-Moran, M., \& Hoy, A. W. (2007). The differential antecedents of self-efficacy beliefs of novice and experienced teachers. Teaching and Teacher Education, 23(6), 944-956. https://doi.org/10.1016/j.tate.2006.05.003

Williams, D., \& Coles, L. (2003). The Use of Research by Teachers: Information literacy, access and attitudes. Retrieved from http://www.nerf-uk.org/word/Fullreport.doc?version=1

Winkler, G. (2001). Reflection and theory: Conceptualising the gap between teaching experience and teacher expertise. Educational Action Research, 9(3), 437-449. https://doi.org/10.1080/09650790100200168

YouTube. (2016). Statistics. Retrieved from https://www.youtube.com/yt/press/statistics.html

Zhang, M., Koehler, M. J., Lundeberg, M., \& Eberhardt, J. (2011). Understanding affordances and challenges of three types of video for teacher professional development. Teaching and Teacher Education, 27(2), 254-262. https://doi.org/10.1016/j.tate.2010.09.015 